\title{
Adobe como saber ancestral usado en construcciones autóctonas de Pore y Nunchía, Casanare (Colombia)
}

\author{
Adobe as an ancestral knowledge used in autochthonous constructions of Pore \\ and Nunchía, Casanare (Colombia)
}

\section{Hernán Rivera-Salcedo}

Fundación Universitaria Internacional del Trópico Americano, Yopal, Casanare (Colombia)

Omar Mauricio Valderrama-Gutiérrez Fundación Universitaria Internacional del Trópico Americano, Yopal, Casanare (Colombia)

\section{Ángel Andrés Daza-Barrera}

Fundación Universitaria Internacional del Trópico Americano, Yopal, Casanare (Colombia)

\section{Gerson Santiago Plazas-Jaimes}

Fundación Universitaria Internacional del Trópico Americano, Yopal, Casanare (Colombia)

Rivera-Salcedo, H. Valderrama-Andrade, 0.-M., Daza-Barrera, A. A. y Plazas-laimes, G.S. (202I). Adobe como saber ancestral usado en construcciones autóctonas de Pore y Nunchía, Casanare (Colombia). Revista de Arquitectura (Bogotá), 23(I), 74-85. https://doi.org/10.14718/RevArq.2021.2762
Hernán Rivera-Salcedo

Licenciado en filosofía, Universidad San Buenaventura. Magister en docencia, Universidad de la Salle. Docente investigador en cultura, patrimonio y saberes ancestrales de la Orinoquía colombiana, adscrito al grupo de investigación Biohábitat, de la Fundación Universitaria Internacional del Trópico Americano (Unitrópico).

(D) https://orcid.org/0000-0002-563I-0564.

https://scholar.google.es/scholar?hl=es\&as_sdt=0\%2C5\&q=Rivera+Salcedo+Hern\%C3\%AIn\&btnG=

(10) hernanrivera@unitropico.edu.co

Omar Mauricio Valderrama-Gutiérrez

Arquitecto, Universidad Católica de Colombia. Especialista en construcción sostenible, Universidad Colegio Mayor de Cundinamarca. Magister en arquitectura bioclimática, ISTHMUS-Escuela de Arquitectura y Diseño de América Latina y el Caribe. Director, Programa de Arquitectura y grupo de investigación Biohábitat, Fundación Universitaria Internacional del Trópico Americano (Unitrópico). Línea de investigación: arquitectura sostenible.

(D) https://orcid.org/0000-000 I-9543-1003

(10) omarvalderrama@unitropico.edu.co

Ángel Andrés Daza-Barrera

Ingeniero Civil de la Fundación Universitaria Internacional del Trópico Americano, Unitrópico.

Especialista en Infraestructura vial, Universidad Pedagógica y Tecnológica de Colombia, Tunja (Colombia)

Adscrito al grupo de investigación Biohábitat.

(D) https://orcid.org/0000-0003-0153-6694

(10) angeldazabarrera@gmail.com

Gerson Santiago Plazas-Jaimes

Ingeniero civil, Fundación Universitaria Internacional del Trópico Americano (Unitrópico). Adscrito al grupo de investigación Biohábitat.

(D) https://orcid.org/0000-000I-952I-0I55.

(a) santiagoplazasjaimes@gmail.com

\section{Resumen}

El adobe es un material de construcción fundamentado en el saber ancestral del acervo popular, y usado principalmente en los sectores rurales colombianos y latinoamericanos. Su utilización, en la mayoría de los casos, está ligada a la dificultad de acceso a materiales convencionales de construcción, generada por la desconexión y el distanciamiento de las zonas urbanas, y a las dificultades económicas propias de dichos sectores de la población; sin embargo, algunas poblaciones han optado por mantener la tradición del uso de este tipo de materiales no convencionales salvaguardando las tradiciones que esto implica. Dada su relevancia popular y sus implicaciones arquitectónicas, se presenta un estudio sobre el uso del adobe en los municipios de Nunchía y Pore, del departamento de Casanare. La metodología aplicada abarca etapas como: observación directa a construcciones en adobe; elaboración de fichas técnicas especializadas hechas a muestras, a partir de ensayos de laboratorio, para el estudio de sus propiedades mecánicas, y aplicación de encuestas semiestructuradas y de entrevistas a personas con experticia en su elaboración. Se busca con este trabajo valorar y salvaguardar el conocimiento ancestral de las técnicas de procesamiento y las propiedades del adobe, como una manifestación patrimonial bajo amenaza de disipación debido al uso de materiales convencionales.

Palabras clave: Conocimientos tradicionales; elemento de mampostería; manufactura; patrimonio cultural; tierra apisonada

\section{Abstract}

Adobe is a construction material based on the ancestral knowledge of the popular acquis, mainly used in the Colombian and Latin American rural territories. In most cases, its use is linked to the difficulty of access to conventional construction materials, generated by the disconnection and distance from urban areas, and the economic difficulties of these sectors of the population. However, some populations have chosen to maintain the tradition of using this type of non-conventional materials, safeguarding the traditions that this implies. Given its popular relevance and architectural implications, it is presented a study on using adobe in the municipalities of Nunchía and Pore of the department of Casanare. The applied methodology includes strategies such as direct observation of adobe constructions, specialized data sheets to samples from laboratory tests for studying its mechanical properties, semi-structured surveys to Nunchía and Pore's people, and individual interviews with experts on its elaboration. This work seeks to value and safeguard the ancestral knowledge of the processing techniques and properties of adobe, like a patrimonial manifestation under threat of dissipation for using conventional materials.

Keywords: Traditional knowledge; masonry unit; manufacture; cultural heritage; rammed earth 


\section{Introducción}

El estudio sobre el uso del adobe en los municipios de Nunchía y Pore, del departamento de Casanare, fue realizado dentro del marco del proyecto Fortalecimiento de capacidades en conocimiento, investigación, ciencia, tecnología e innovación, bajo la convocatoria del convenio 020/2013, suscrito entre la Gobernación de Casanare y la Corporación Unificada de Educación Superior (CUN), trabajo ejecutado por integrantes del grupo de investigación Biohábitat y con el acompañamiento de la coordinación técnica de investigación de la Fundación Universitaria Internacional del Trópico Americano (Unitrópico).

El adobe es un material de construcción ancestral, cuyo uso ha disminuido considerablemente, dado el uso de alternativas convencionales y modernas. Inicialmente fue considerado una alternativa popular práctica para resolver la falta de vivienda en las comunidades menos favorecidas o aisladas, pero actualmente su uso genera una percepción asociada a condiciones de baja calidad de vida. La riqueza cultural del adobe y sus bondades como material sostenible, relacionadas con la facilidad de obtención de su materia prima y su bajo costo, han perdido valor y reconocimiento social, traducido ello en la poca conservación del saber ancestral y la apatía de las nuevas generaciones, a lo que aduce Barada al hablar sobre las técnicas tradicionales de construcción: "este campo no solo se va viendo circunscripto en tanto muchos jóvenes ya no aprenden las técnicas utilizadas por sus padres y abuelos y por lo tanto existe un determinado conocimiento que se va perdiendo" (2016, p. 51).

En Suramérica, ciudades pioneras en la construcción con adobe, como Lima (Perú), han elaborado manuales con especificaciones técnicas para la edificación de viviendas seguras y sismorresistentes en adobe. Los antecedentes históricos desarrollados y los problemas estructurales comunes a este tipo de vivienda precisan procedimientos descritos en el manual para la selección y la mezcla óptimas de materiales a través de ensayos prácticos in situ, además de describir el proceso constructivo del bloque de adobe, las especificaciones para los cimientos, los muros, los techos, la albañilería, los amarres, los refuerzos y los revestimientos, entre otros (Morales-Morales et al., 1993, pp. 42-57).

La construcción en adobe se ha convertido en patrimonio de familias humildes, y se mantiene viva en países como Argentina, Bolivia, Colombia, Ecuador, México y Perú, entre otros. En Colombia, por ejemplo, se la usó originalmente como solución habitacional de familias pudientes en la construcción de edificios institucionales e iglesias, pero entra en desuso entre las décadas de 1920 y 1940, debido a que el país da "un salto a la modernidad" dejando de ser una nación rural para convertirse en urbana, que considera la tierra cruda como un atavismo de la sociedad moderna" (Rivero-Bolaños, 2007, pp. 354-356).

Para Villacampa-Crespo et al. (2018, pp. 30-36), el concepto de arquitectura en relación con el lugar ahora se ha perdido, mientras que la globalización ha permitido construir cualquier tipo de construcción en cualquier lugar; por ello, el objeto de la presente investigación está orientado, como ya se dijo, a valorar y salvaguardar el conocimiento ancestral de las técnicas de procesamiento y las propiedades del adobe, como una manifestación patrimonial bajo amenaza de disipación debido al uso de materiales convencionales.

\section{Construcciones de adobe en Colombia}

El adobe ha sido estudiado y catalogado como una manifestación tradicional más que como arquitectura contemporánea, lo que ha llevado a su desuso, por la falta de una normatividad nacional que permita la validación del conocimiento formal constructivo y que, además, revalorice la tierra cruda como material apto para la construcción de viviendas urbanas y rurales.

Según las estadísticas del tercer Censo Nacional Agropecuario (CNA) realizado en Colombia por el Departamento Administrativo Nacional de Estadística (DANE), en 2014 cerca del 49,1\% de las viviendas ocupadas en el área rural dispersa del país tiene como material predominante en sus paredes bloque, ladrillo, piedra o madera pulida; les siguen: con el 25,5\%, materiales como tapida pisada, adobe o bahareque; con el $18,9 \%$, tabla burda, tabla o tablón; con el 3,4\%, guadua, caña, esterilla u otros vegetales, y con el $3,1 \%$, otros tipos de materiales (materiales prefabricados, teja, cartón, latas, zinc, desechos, plásticos o sin paredes). En Casanare, el adobe en las paredes para las viviendas rurales es usado en cerca del $18 \%$ de los casos, sin mencionar las viviendas situadas en caseríos o asentamientos urbanos que no hacen parte del censo. En contraste con los datos obtenidos por el DANE en 2005, los materiales predominantes en paredes de la vivienda rural, como bloque, ladrillo, piedra o madera pulida pasaron del $41,3 \%$ al $48,5 \%$ con respecto al censo de 2014, y en el caso de la tapia pisada, el adobe y el bahareque, su uso disminuye del $31,9 \%$ el $25,2 \%$, lo cual permite inferir que se ha venido reemplazando este material con la inclusión de materiales industriales (Departamento Administrativo Nacional de Estadística, 2015).

Desde una mirada por regiones, en la ciudad de Bogotá, D. C., hasta mediados del siglo XIX se erigieron torres de numerosas iglesias y casonas a partir de adobe, tapia pisada, ornamentos en madera y adoquines, que fueron, los principales materiales en aquel tiempo para la construcción del área urbana, y ayudaron a definir el adobe como marca del patrimonio inmaterial de 


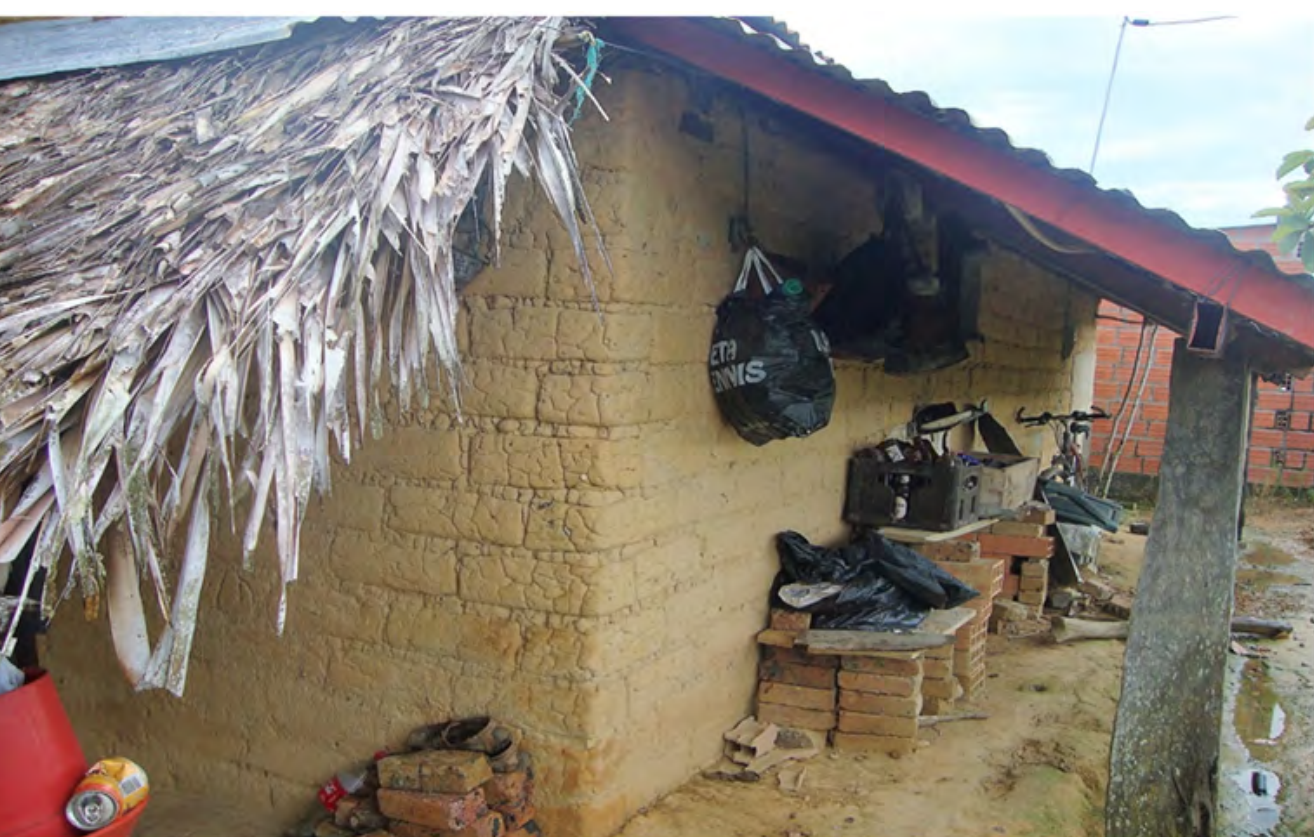

(4) Figura 1. Vivienda en adobe de Nunchía.

Fuente: Rivera et al. (2018). CC BY-NC-ND.

Colombia. Este legado español ha sido plasmado a partir de la época colonial, que consolidó estilos de construcciones arquitectónicas implantadas en los pueblos con fines religiosos, socioculturales, económicos y políticos. Tras la época de la independencia, la capital atravesó un lapso de quietud en actividades constructivas, para priorizar la restauración de edificaciones y la ejecución de obras de menor rango; esto también, a causa de la carencia de profesionales españoles en obras civiles. Solo fue hasta después de 1840 cuando empezaron a adoptarse nuevos estilos y formas de construcción, procedentes de las transformaciones industriales internacionales, pues en medio de las controversias ideológicas de los partidos Liberal y Conservador sobresalían el pensamiento y la necesidad de abrir paso a la cultura del mundo occidental (Castiblanco-Roldán, 2009, pp. 54-55).

En la región de la Orinoquía colombiana, integrada por los departamentos de Arauca, Casanare, Meta, Guaviare y Vichada, el hogar Ilanero es una combinación entre la vivienda indígena y los modelos estructurales que aportaron los jesuitas en el siglo XVII, y donde los principales materiales de construcción son el adobe, el bahareque o la tapia pisada, los techos de palma y las puertas y ventanas en madera.

\section{Viviendas autóctonas en los municipios de Pore y Nunchía}

Es importante conocer el desarrollo de los métodos constructivos implementados hace cientos de años, porque promueven el valor de las tradiciones y las manifestaciones culturales contenidas en el adobe como material constructivo. Municipios como Pore, fundado en 1644, y Nunchía, en 1655, han utilizado el adobe para la instauración de sus primeras edificaciones, que, a pesar del paso del tiempo siguen en pie, lo cual demuestra su eficiencia como sistema de construcción, lo que en términos de Morales-Galaviz se enuncia:
Dado que la arquitectura vernácula es la que se desarrolla de manera colectiva por los nativos de cierta región, la gente toma los materiales existentes en su entorno y son materiales que fomentan la sustentabilidad puesto que son materiales que no requieren ser transportados, se adaptan de manera eficaz al clima y son materiales fáciles de manejar en sistemas constructivos sencillos que las personas han conocido y que son herencia de las generaciones anteriores. (2017, p. 20)

Nunchía, ubicado en el piedemonte llanero, hace uso masivo del adobe y la tapia pisada como materiales de construcción. Las viviendas de la región conservan rasgos tradicionales, pues se caracterizan por el uso de materiales que ofrece la tierra. Hay viviendas urbanas de una planta con muros construidos, principalmente, en tierra cruda usada en el $56 \%$ del total de las edificaciones del municipio; en materiales industriales, en el $39 \%$, y en madera burda y zinc, en el 4\% (Decreto DA0100.02.01.022, 2012). El uso de materiales industriales en la construcción no ha cambiado la percepción de los habitantes de Nunchía respecto al adobe, aunque la edificación cesó por la falta de licencias de construcción.

La tranquilidad percibida en este municipio, conocido como "la tierra del duende", es una perfecta combinación entre calles empedradas y casonas construidas en tapia pisada y adobe, como se muestra en la figura 1. Sus habitantes, hombres y mujeres humildes, abren amablemente sus puertas a los investigadores, y dejan a disposición sus conocimientos empíricos relacionados con las construcciones autóctonas.

En Pore se observó que los materiales predominantes de construcción en las viviendas en el casco urbano son bloque o ladrillo para las paredes, zinc para los techos y cemento para los pisos. En el área rural, las viviendas pueden parecer precarias a los ojos del observador inexperto, al estar construidas en materiales extraídos del medio natural; a saber, piso de tierra, techos de paja y paredes de bahareque. No obstante, las condiciones de la estructura de la vivienda son óptimas para su habitabilidad. Además, se deducen el arraigo cultural del modus vivendi de los campesinos y el aprovechamiento de la diversidad de materiales que ofrece el territorio para la construcción tradicional de la vivienda llanera, que por sus ventajas bioclimáticas y bioenergéticas es considerada por sus habitantes confortable y segura, así como lugar para protegerse de enfrentamientos violentos como consecuencia del conflicto armado en Colombia.

\section{Metodología}

\section{Población y muestra}

La población del presente estudio viene de la participación de 2 municipios del departamento de Casanare, que son considerados patrimonio cultural de la nación. Por una parte, la Ley 936 del 30 de diciembre de 2004, en su artículo 1 
declara como patrimonio histórico cultural de la nación el municipio de Pore, en el departamento del Casanare, lo cual es ratificado por la Resolución 3914 de 2014, que adopta el Plan Especial de Manejo y Protección (PEMP) del complejo arquitectónico conformado por las ruinas de la antigua iglesia de Pore, la edificación conocida como "la cárcel" y el túnel que comunica estas dos construcciones del municipio y su zona de influencia, y declarados bien de interés cultural del ámbito nacional (Resolución 3914, 2014).

El municipio de Nunchía, además de caracterizarse por una población rural que conserva saberes ancestrales de sus gentes en los aspectos constructivos, ha sido protagonista de la historia del país por hacer parte de la ruta donde las tropas libertadoras fueron acogidas por sus pobladores, lo cual se exalta como patrimonio cultural de la nación por la Ley del Bicentenario de la Independencia (Ley 1916, 2018).

La muestra del estudio fue representada por 150 adultos mayores de los municipios de Pore y Nunchía, quienes han tenido interacción directa con el uso y la fabricación de construcciones de adobe, así como personas con experticia en el tema, y que, preferiblemente, viven en edificaciones de unidades de mampostería en tierra cruda.

A partir de la muestra seleccionada se obtuvo información relevante del conocimiento autóctono que se ha impartido como herencia cultural en la comunidad. Se estudiaron especímenes de bloques de adobe, cada uno de ellos con una edad diferente - de acuerdo con la información de los portadores del saber ancestral sobre la antigüedad de uso de las viviendas-, y los cuales fueron objeto de estudio en relación con la caracterización física, mecánica y química de estos. Se fabricaron doce especímenes siguiendo las técnicas usadas por los pobladores.

\section{Recolección de la información}

En la investigación se aplicaron instrumentos como la entrevista, la encuesta semiestructurada, la observación directa y ensayos de laboratorio. La entrevista se realizó de manera individual, teniendo en cuenta criterios como la relación directa con el tipo de edificaciones, ya sea desde su habitabilidad hasta la observación y la elaboración del adobe. Se indagó sobre la experiencia adquirida a lo largo de la vida, y la manera como aprendieron e instruyeron a las actuales generaciones en los campos afines a la construcción de viviendas en tierra cruda.

La encuesta semiestructurada se aplicó de manera individual en las residencias de los portadores con el registro de los datos por parte del investigador. Contiene diez preguntas con múltiple respuesta, y la información suministrada por la muestra - anteriormente definida - relaciona lineamientos generales como experiencias, aprendizaje y prácticas constructivas. La expe- riencia contribuye a identificar el nivel de aproximación o acercamiento del individuo con el objeto de estudio; es decir, con las construcciones en adobe; el aprendizaje abarca los medios por los cuales fue adquirido dicho conocimiento y las prácticas constructivas muestran los aspectos más importantes en la correcta manufactura del mampuesto, según el saber trasmitido. Finalmente, el encuestado ilustra sobre las posibles causas del desuso actuales y el deterioro de las construcciones elaboradas en adobe, así como la aprobación o rechazo en la promoción de este conocimiento entre la población juvenil.

La observación directa permite la inmersión de los investigadores en el campo, a través de mediciones directas. Lo anterior, en primera instancia, establece vínculos de confianza, respeto y hospitalidad con los portadores del saber ancestral y otros sectores de la comunidad; en segundo lugar, permite obtener información relevante con respecto al uso del adobe como unidad de mampostería en Pore y Nunchía. De la misma forma, este proceso permitió identificar construcciones antiguas que aún se encuentran habitadas y verificar las condiciones de vida y el entorno de estas, sus usos y sus diseños arquitectónicos, así como la toma de muestras o especímenes de bloques, los cuales fueron analizados con ensayos de laboratorio para determinar sus características físicas, mecánicas y químicas.

La técnica, que emplea ensayos de laboratorio, se realizó siguiendo el método de bouyoucos (textura y composición del suelo), las normas de ensayo de materiales 2013 del Instituto Nacional de Vías (Invías) —en cuanto a humedad, plasticidad y resistencia a la compresión simple- y la determinación de $\mathrm{pH}$, todo lo cual constituye un factor cuantitativo para la caracterización del adobe como elemento de mampostería. La medición de las características físicas, mecánicas y químicas, permite comparar y conocer con rigurosidad sus propiedades frente a los materiales convencionales empleados en la construcción.

\section{Resultados}

El análisis de los resultados se hizo a partir de la información obtenida con la aplicación de los instrumentos validados y utilizados, que contribuyen a valorar el adobe como elemento base del sistema constructivo de las viviendas autóctonas, y los cuales se describen a continuación.

\section{El saber de los portadores acerca del adobe}

La información obtenida por los portadores mediante las encuestas semiestructuradas hace alusión a las experiencias, los conocimientos, los saberes técnicos y la percepción frente la situación actual del sistema constructivo con base en tierra cruda o adobe. Las interacciones de los portadores del saber ancestral en relación con las construcciones presentan mayor correspondencia 
(1) Tabla 1. Encuesta realizada a los pobladores de los municipios de Pore y Nunchía. Fuente: Rivera et al. (2018). con la habitabilidad de la vivienda, y se destaca que el tiempo en el cual se dio inicio a estas prácticas constructivas en Casanare datan de hace más de 100 años, conocimiento que ha sido adquirido a través de antepasados o familiares y con la experiencia laboral. Se evidencia que, además de la tierra no cernida y el agua, el aditivo más uti- lizado es el pasto, y que el proceso de secado se da con el calor del sol. Los pobladores manifiestan que las causas atribuibles al deterioro son la falta de cimiento en los muros, las altas temperaturas, la antigüedad y la exposición a la humedad (entradas de agua), y por otra parte, que las razones del abandono de la vivienda son la adopción de

\begin{tabular}{|c|c|c|c|}
\hline & No. de encuestados: 150 personas & Municipios: Nunchía y Pore & SS 0 más \\
\hline No. & Pregunta & Respuesta & Porcentaje \\
\hline \multirow{4}{*}{1} & \multirow{4}{*}{$\begin{array}{l}\text { ¿Qué interacción ha tenido usted con construcciones } \\
\text { en adobe? }\end{array}$} & Habitado & $50 \%$ \\
\hline & & Construido & $27 \%$ \\
\hline & & $\begin{array}{l}\text { Visto: (este término hace alusión a la observación como única } \\
\text { forma de interacción de los pobladores con estas construcciones) }\end{array}$ & $0 \%$ \\
\hline & & Construido y habitado & $23 \%$ \\
\hline \multirow{4}{*}{2} & \multirow{4}{*}{$\begin{array}{l}\text { ¿Hace cuantos años cree que se empezó a usar este } \\
\text { método de construcción en el departamento de } \\
\text { Casanare? }\end{array}$} & Menos de 50 años & $0 \%$ \\
\hline & & Entre 50 y 100 años & $13 \%$ \\
\hline & & Hace más de 100 años & $87 \%$ \\
\hline & & No sabe & $0 \%$ \\
\hline \multirow{3}{*}{3} & \multirow{3}{*}{ ¿De dónde proviene su conocimiento sobre el adobe? } & Experiencia laboral & $30 \%$ \\
\hline & & Sus antepasados o sus familiares & $53 \%$ \\
\hline & & Terceros (maestros de construcción, técnicos u otros) & $17 \%$ \\
\hline \multirow{6}{*}{4} & \multirow{6}{*}{$\begin{array}{l}\text { Además de tierra y agua, ¿qué otro material se } \\
\text { adicionaba para la elaboración de un bloque de } \\
\text { adobe? }\end{array}$} & Bosta & $3 \%$ \\
\hline & & Pasto & $70 \%$ \\
\hline & & Arena gruesa & $0 \%$ \\
\hline & & Todas las anteriores & $0 \%$ \\
\hline & & Ninguna de las anteriores & $13 \%$ \\
\hline & & Bosta y pasto & $13 \%$ \\
\hline \multirow{3}{*}{5} & \multirow{3}{*}{ Para el proceso de secado del adobe se prefería } & Proteger del sol y el viento & $7 \%$ \\
\hline & & Rociar con arena fina & $10 \%$ \\
\hline & & $\begin{array}{l}\text { Dejar los bloques sobre lugares alejados de la humedad del suelo } \\
\text { y el aire }\end{array}$ & $3 \%$ \\
\hline \multirow{4}{*}{6} & \multirow{4}{*}{$\begin{array}{l}\text { ¿Cuáles cree que son las causas del deterioro de las } \\
\text { casas de adobe? }\end{array}$} & Mala mano de obra & $13 \%$ \\
\hline & & Falta de cimientos o de bases en los muros & $43 \%$ \\
\hline & & Altas temperaturas; antigüedad; entrada de agua & $37 \%$ \\
\hline & & Falta de pega (revoque) en las paredes & $7 \%$ \\
\hline \multirow{2}{*}{7} & \multirow{2}{*}{$\begin{array}{l}\text { ¿La tierra usada para hacer bloques de adobe era } \\
\text { cernida? }\end{array}$} & Sí & $0 \%$ \\
\hline & & No & $100 \%$ \\
\hline \multirow{3}{*}{8} & \multirow{3}{*}{$\begin{array}{l}\text { ¿Por qué cree que algunas edificaciones han sido } \\
\text { abandonadas? }\end{array}$} & Eran inseguras para vivir & $7 \%$ \\
\hline & & Por los beneficios que ofrecen los materiales industriales & $57 \%$ \\
\hline & & $\begin{array}{l}\text { Por desconocer los procesos de mantenimiento y reparación de } \\
\text { casas en adobe }\end{array}$ & $37 \%$ \\
\hline \multirow{2}{*}{9} & \multirow{2}{*}{$\begin{array}{l}\text { ¿Estaría interesado en aprender un método técnico de } \\
\text { construcción del adobe? }\end{array}$} & Sí & $70 \%$ \\
\hline & & No & $30 \%$ \\
\hline \multirow{2}{*}{10} & \multirow{2}{*}{$\begin{array}{l}\text { ¿Cree usted que debe existir un manual técnico sobre } \\
\text { construcciones en adobe? }\end{array}$} & Sí & $97 \%$ \\
\hline & & No & $3 \%$ \\
\hline
\end{tabular}


materiales industriales, junto con la ausencia del conocimiento sobre el adecuado mantenimiento de dichas construcciones, por lo cual expresan un interés de aprendizaje en técnicas constructivas y en la imperiosa necesidad de tener a su alcance un manual técnico sobre construcciones en adobe, como se muestra en la tabla 1.

Lo manifestado por los portadores en las entrevistas ha sido con la garantía de que la identidad personal y el uso de la información aportada se usarán con fines académicos y de carácter público. Se observa que las generaciones anteriores, portadoras de este saber, no dependían de industrias ni de equipos especializados; las obras que edificaban eran de carácter autoconstructivo y los mismos propietarios se hacían cargo de las tareas de mantenimiento de los muros de adobe.

Además de lo anterior, se ha documentado que las primeras edificaciones en la región fueron realizadas en adobe, pero al pasar el tiempo esta práctica se ha ido perdiendo, debido a la llegada de materiales industriales como el bloque, el hierro y el cemento; aun así, existen viviendas construidas en este material (adobe) que todavía mantienen su vida útil. F. Silva, de 75 años de edad, poblador y oriundo del municipio de Pore, comenta: "He pasado toda mi vida en una casa de adobe, ubicada en la calle 2 con carrera 19, la cual me fue heredada por mi madre" (comunicación personal, 10 de agosto de 2017).

En el mismo sector del municipio se observan viviendas en estado de deterioro total que, sin embargo, se mantienen en pie, caso visto, por ejemplo, en la calle 3 con carrera 16, donde se encuentra una residencia en adobe, la cual fue abandonada desde 2013, como se muestra en la figura 2, a causa de los visibles daños estructurales, y que, según el relato de J. Granados, fue la casa que habitó su padre desde sus 5 años de edad, y quien falleció en 2012, a sus 92 años. Este evento permitió determinar la antigüedad de la vivienda $y$, por ende, la resistencia de los materiales en tierra cruda utilizados para su construcción (J. Granados, comunicación personal, 15 de junio de 2017).

Ni la percepción errónea de que las construcciones en tierra no son rentables a mediano y largo plazo ni la creencia de que son asociadas a la pobreza constituyen impedimento para que adultos, jóvenes, hijos y nietos de los portadores del saber ancestral manifiesten su interés en aprender sobre esta técnica constructiva. En tal sentido, E. Estepa expresa: "Hace veinte años se construyó la residencia a partir de adobe, visualmente es agradable y cuenta con acabados arquitectónicos, pisos en cerámica, cielo raso y muros estucados que permiten experimentar cambio de la temperatura ambiente con características bioclimáticas" (comunicación personal, agosto de 2017).

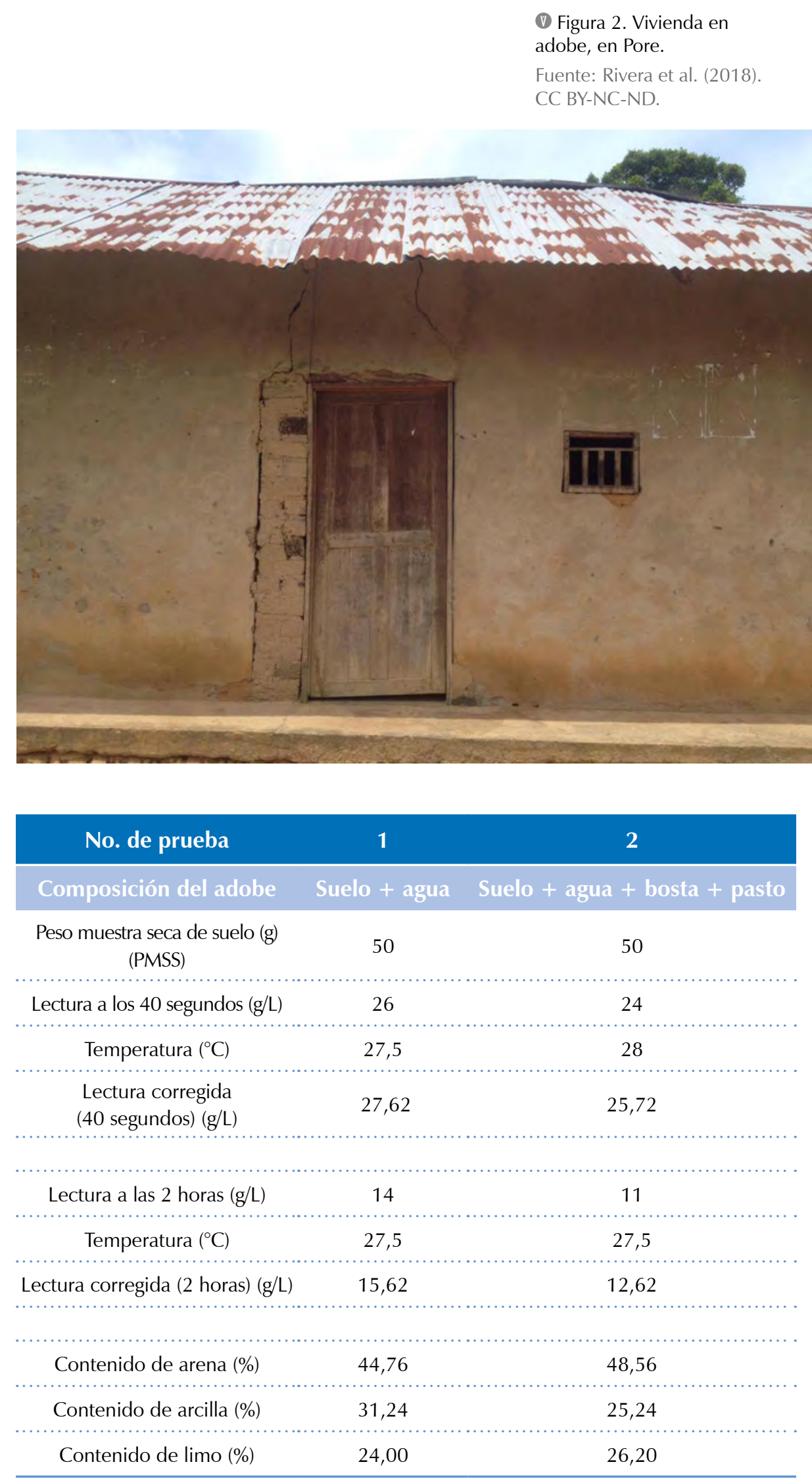

\section{Propiedades fisicomecánicas y químicas, y etapas utilizadas en la elaboración del adobe}

A Tabla 2. Determinación de textura (método bouyoucos). Fuente: Rivera et al. (2018).
El adobe es uno de los materiales más antiguos todavía en uso; en diferentes partes del mundo se pueden encontrar hoy en día construcciones a base de tierra sin cocer. $\mathrm{Al}$ ser un conocimiento tradicional, los métodos constructivos asociados al adobe han sido objeto de constantes alteraciones, lo que obedece a las necesidades y los beneficios que ofrece cada territorio, como el clima, 
las costumbres de sus habitantes, el suelo y la mano de obra disponible. Añádese a esto que al revisar las técnicas utilizadas por los pobladores de Pore y de Nunchía para la elaboración de un adobe, en dicho proceso los moradores se centran en cuatro etapas: 1) la selección de los materiales, 2) el proceso de mezclado, 3) el sistema de moldeo y 4) las condiciones del proceso de secado.

Las pruebas de laboratorio permitieron establecer las propiedades fisicomecánicas y químicas involucradas en la elaboración de un bloque de adobe tradicional, lo que contempla, en cuanto a la selección de materiales, la elección de un suelo con textura franco-areno-arcillosa y una distribución porcentual del $47 \%$ de arenas, el $28 \%$ de arcillas y el $25 \%$ de limos, parámetros que son un promedio procedente del ensayo de laboratorio de propiedades físicas denominado método de bouyoucos realizado a dos especímenes, como se muestra en la tabla 2.

Con base en los resultados observables en la tabla 2, se infiere que los porcentajes de textura son congruentes con la inspección visual realizada por los distintos portadores. Las cualidades físicas de la arcilla facilitan la selección minuciosa de las partículas que componen la mezcla, por lo que la extracción de este material del suelo se empleaba sin modificaciones, por lo cual se deduce que se ha conservado el saber ancestral relacionado con la experticia para la localización del material en un terreno natural.

La determinación de las propiedades químicas para la construcción del bloque de adobe se evidencia con un pH óptimo $(5,67)$, que se obtuvo con la mezcla de suelo, agua, bosta y pasto. Por otra parte, la mezcla de suelo y agua arrojó un valor de $\mathrm{pH}$ equivalente a 4,68 ; es decir, por fuera del rango normal $(5,5$ y 7,0$)$ para la mayoría de los suelos con cobertura vegetal. Lo anterior es indicativo de la poca relevancia que le otorga el portador del saber ancestral a la acidez del suelo en la elaboración del espécimen y, por el contrario, de los beneficios de los aditivos naturales para el aumento de su cohesión, como se muestra en la tabla 3.

La humedad de la mezcla entre el suelo y el agua (esta última, libre de residuos sólidos o sedimentos, además de ser incolora e insípida) debe estar entre el $10 \%$ y el $20 \%$, a lo que se pueden agregar aditivos naturales que ayuden a mejorar la consistencia y la estabilidad de las unidades de mampostería: por ejemplo, el pasto, la bosta o el tamo de arroz (información adicional obtenida por los portadores).

En países como Perú, la normatividad existente en construcciones de adobe - específicamente, la Norma E.080 Diseño y construcción con tierra reforzada, artículo 8. Esfuerzos de rotura mínimos. Ensayos de laboratorio- denota que la unidad de mampostería debe poseer una resistencia a la compresión de $10,2 \mathrm{~kg} / \mathrm{cm}^{2}$ para que este soporte un evento sísmico. Se debe tener en cuenta que dicho valor proviene del fallo de bloques con modificaciones técnicas (Ministerio de Vivienda, Construcción y Saneamiento, 2017); sin embargo, los resultados de laboratorio oscilan entre 5,22 y $8,55 \mathrm{~kg} / \mathrm{cm}^{2}$, lo cual corresponde a la resistencia de los adobes en relación con la compresión simple sin modificaciones técnicas, como se muestra en la tabla 4.
๑ Tabla 3. Determinación de pH. Fuente: Rivera et al. (2018)

\begin{tabular}{ccc} 
No. de prueba & $\mathbf{1}$ & $\mathbf{2}$ \\
Composición & Suelo + agua & Suelo + agua + bosta + pasto \\
\hline Lectura con potenciómetro & 4,68 & 5,67 \\
\hline
\end{tabular}

\begin{tabular}{|c|c|c|c|c|}
\hline \multicolumn{5}{|c|}{ Resistencia a la compresión simple } \\
\hline Espécimen & $\begin{array}{c}\text { Área } \\
\text { transversal } \\
\left(\mathrm{cm}^{2}\right)\end{array}$ & $\begin{array}{c}\text { Lectura } \\
\text { de falla (kgf) }\end{array}$ & $\begin{array}{c}\text { Resistencia a } \\
\text { la compresión } \\
\left(\mathrm{kgf} / \mathrm{cm}^{2}\right)\end{array}$ & $\begin{array}{l}\text { Resistencia a la } \\
\text { compresión (PSI) }\end{array}$ \\
\hline 1 mes $($ suelo + agua + bosta + pasto $)$ & 48,44 & 261,05 & 5,39 & 76,66 \\
\hline 1 mes (suelo + agua) & 23,03 & 196,81 & 8,55 & 121,61 \\
\hline 3 años (suelo + agua) & 20,35 & 151,47 & 7,44 & 105,82 \\
\hline 30 años (suelo + agua)* & 34,84 & 195,07 & 5,60 & 79,65 \\
\hline 70 años (suelo + agua)* & 22,32 & 151,43 & 6,78 & 96,43 \\
\hline 100 años (suelo + agua)* & 33,92 & 176,92 & 5,22 & 74,25 \\
\hline
\end{tabular}

$\otimes$ Tabla 4. Resultados de resistencia a la compresión simple

Fuente: Rivera et al. (2018). 
Por lo expuesto, es posible enfatizar en el mejoramiento de la capacidad de resistencia del adobe modificando aspectos como el tipo de suelo, la presencia o no de aditivos naturales, la selección de la composición porcentual de arenas, limos y arcillas, la priorización del uso de la humedad óptima para los procesos de mezclado y obtención de la mayor densidad máxima permisible; todo ello, a fin de lograr una resistencia más alta a la compresión, que promueva su durabilidad ante el sometimiento de cargas y la resistencia ante catástrofes naturales (Duarte et al., 2018).

Saroza et al. (2008) afirman que en la mezcla de adobe es conveniente utilizar suelos con un bajo índice de plasticidad, teniendo en cuenta que mientras más alto sea este, mayor será la cantidad de agua contenida en la masa que lo convierte en moldeable, y una vez seco, se tendrán mayores retracciones, por cuanto evaporará un volumen mayor de agua. La recomendación constructiva fue aplicada a la mayoría de los especímenes encontrados, por medio del ensayo de límites de Atterberg, lo cual respalda su aplicación y sus excelentes beneficios. El presente estudio relaciona las diferentes formas para la mezcla del material de acuerdo con la observación directa; a saber: mezcla manual, o con animales (equinos y bovinos) o con los pies, como se muestra en la figura 3.

Después de analizar las entrevistas, las encuestas semiestructuradas, las pruebas de laboratorio y la observación directa aplicadas a los portadores del saber, se presenta en la figura 3 la propuesta del proceso de las etapas para la elaboración del adobe, según los datos obtenidos.

Terminado el proceso de mezcla de materiales, se dispone de moldes o gaveras elaborados en madera, similares en su forma a los empleados en Egipto y Perú, halladas desde hace cientos de años (Torres-Peceros, 2018), que permiten la elaboración del bloque y cuyas dimensiones, según el trabajo en campo, se encuentran en el rango de 30-40 cm de largo, $15-20 \mathrm{~cm}$ de ancho y $10-12 \mathrm{~cm}$ de alto.

En cuanto a las condiciones del proceso de secado - el cual consiste en el tiempo en que el bloque de mampostería adquiere la resistencia necesaria para ser usado en la construcción-, se debe disponer el espécimen en una superficie plana, sin irregularidades que puedan modificar su forma o su textura; dicha superficie, además, debe estar limpia y seca, para así prevenir que el adobe sea contaminado, y sus propiedades específicas alteradas, por la presencia de humedad. Se dispondrán al sol los bloques durante, mínimo, 3 días en el sitio de elaboración, antes de ser apilados; posteriormente, se los almacenará entre 20 y 30 días, y luego, pueden ser usados en cualquier tipo de construcción. De igual manera, se adiciona arena fina a la superficie del bloque, para crear una capa de protección y evitar el agrietamiento, como se muestra en la figura 4.

(1) Figura 3. Selección de materiales y proceso de mezclado del adobe. Fuente: Rivera et al. (2018) CC BY-NC-ND.
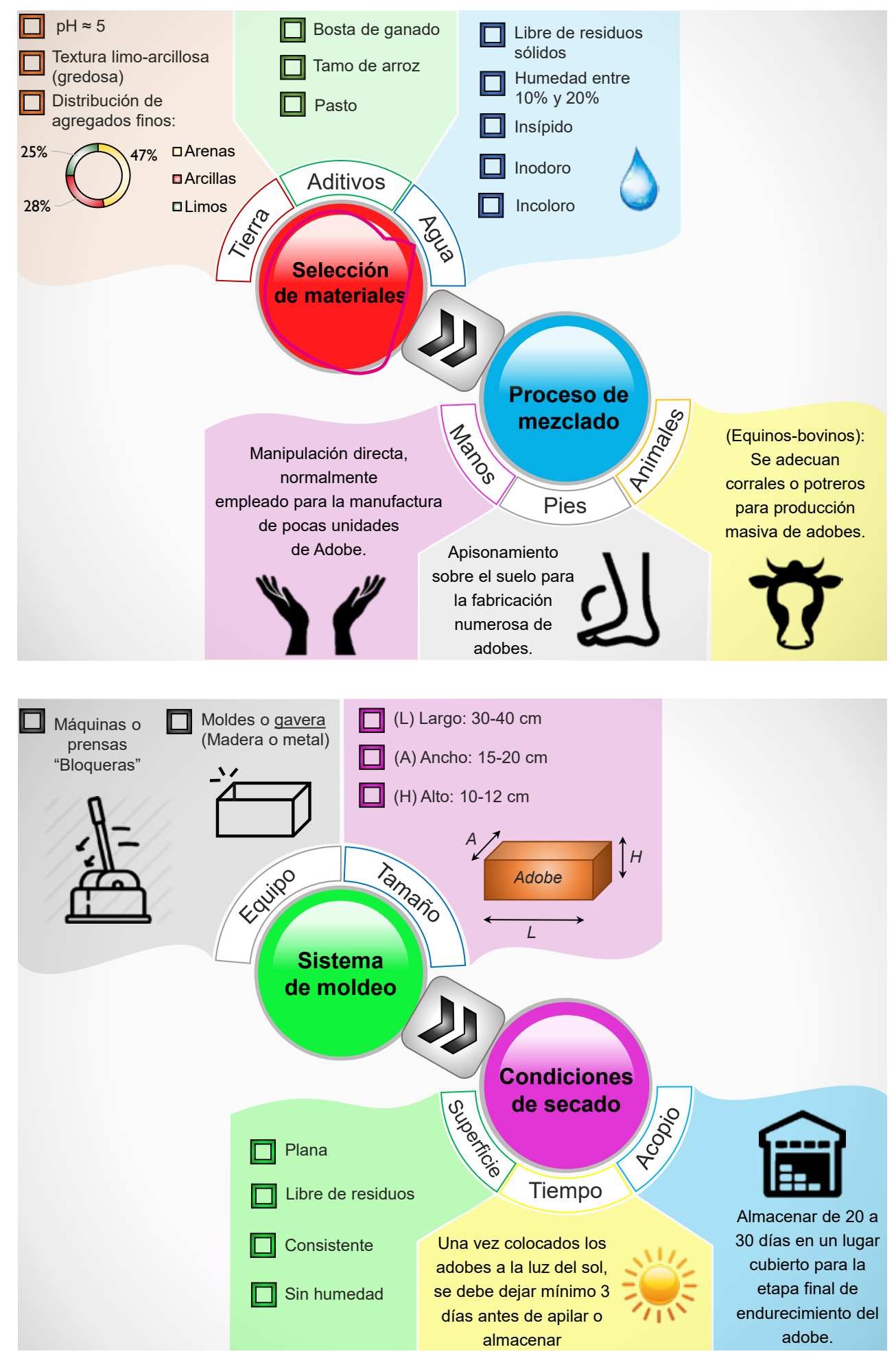

\section{Arquetipo de vivienda autóctona en adobe}

Dado que el adobe es un material fundamental en la construcción de viviendas, por el aporte que hace a las condiciones ambientales, sociales, habitacionales y actitudinales, se presenta la propuesta de arquetipo de vivienda autóctona del hogar llanero de los municipios objeto del presente estudio, como se muestra en la figura 5.

Los resultados obtenidos establecen una relación con el modo de vida del individuo en su entorno, tal como se expresa por los portadores entrevistados que conciben la vivienda como el 
$\otimes$ Figura 5. Arquetipo de vivienda autóctona en adobe.

Fuente: Rivera et al. (2018).

CC BY-NC-ND.

a. Armazón, o estructura de techo (puntal, viguetas, riostra, viga de amarre, etc.), en madera de cedro.

b. Sistema de anclaje con tapas metálicas de botellas.

c. Revoque de tierra o cemento, con acabado en pintura.

d. Cimiento ciclópeo con piedra (3"-9") y tierra.

e. Terreno natural.

f. Puertas y ventanas abatibles doble hoja, en madera de cedro.

g. Mortero de piedra.

h. Muro en bloque de adobe.

i. Tipo de techo en palma de vino (Attalea butyracea)/palma real (Roystonea regia).

j. Tipo de techo en lámina de zinc.

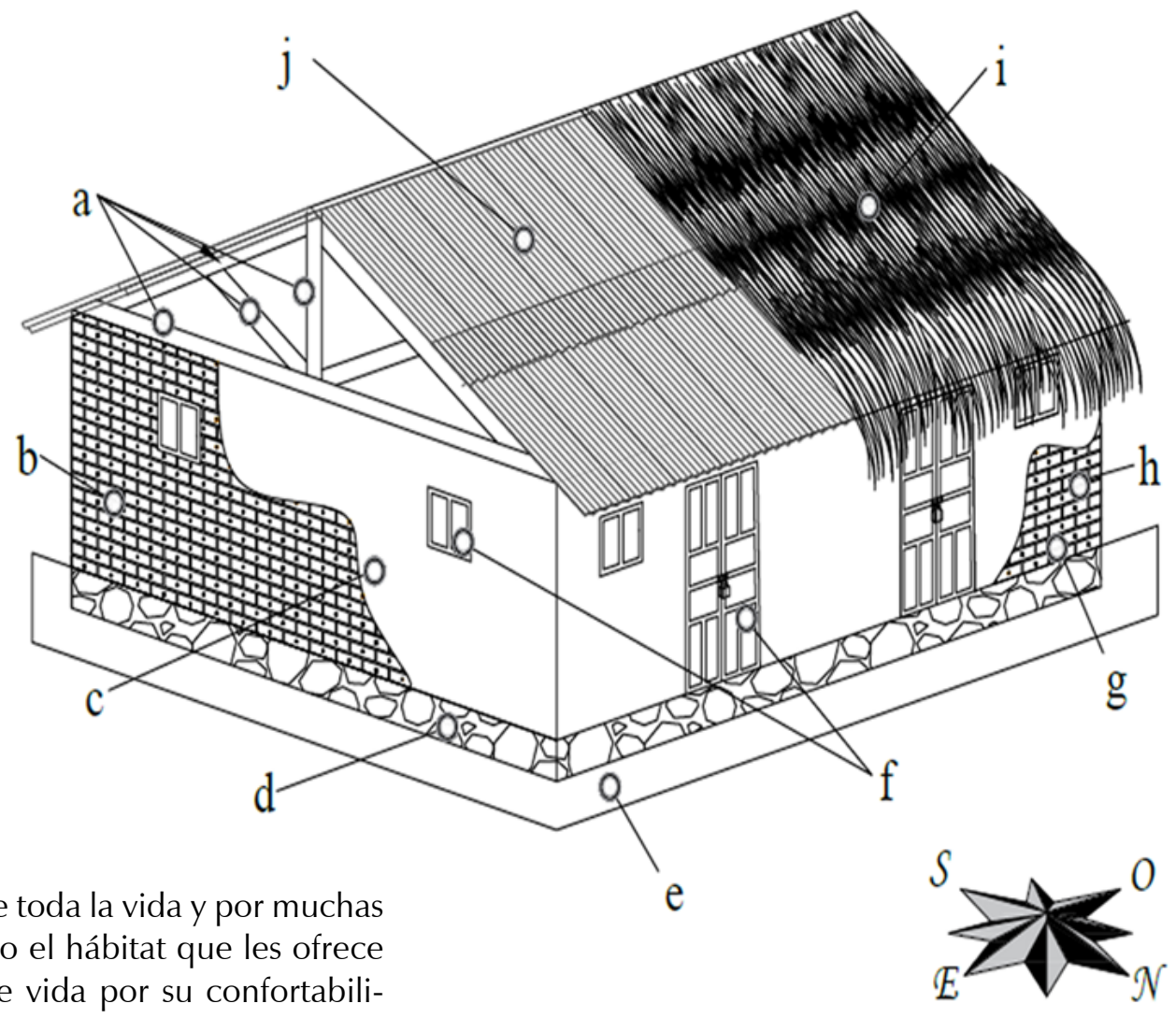
de vida por su confortabilidad desde lo estético y la sensación térmica, lo cual se corrobora desde la noción de la psicología ambiental manifestada por Martínez-Soto: "las ciudades no son solamente escenarios delimitados geográficamente, sino espacios donde acontecen determinadas experiencias, percepciones y significados" (2019, p. 48).

La vivienda autóctona se caracteriza por: cimientos ciclópeos sobre el terreno natural, como se observa en el literal e de la figura 5, constituidos por la combinación del barro o greda y piedras de diferentes tamaños, las cuales fluctúan entre un rango de 3-9 pulgadas, según se ve en el literal $d$ de la figura 5. En cuanto a los muros, se pudo observar que estaban compuestos por bloques de adobe adheridos entre sí por un mortero de pega a base de greda, tal como se ve en los literales $g$ y $h$ de la figura 5 .

Las puertas y las ventanas son abatibles doble hoja y construidas en cedro, material con el cual se construye también el armazón, o cubierta, como se pudo apreciar en el literal $f$ de la figura 5. Esta madera debe ser cortada en menguante, pues durante dicha fase lunar, el frío y la oscuridad de la noche contraen la savia del árbol, lo cual permite que el secado de la madera sea más rápido, uniforme y con una menor probabilidad de que se arquee al secarse (Varela, 2014).

El techo puede estar conformado por láminas de zinc (material más utilizado actualmente) o en palma real (método más aplicado en la antigüedad por los pobladores de Casanare), según se ve en los literales $i$ y $j$ de la figura 5, pues, según personas que habitaron este tipo de edificaciones, la palma es un gran aislante térmico, pero su uso ha disminuido por la facilidad de que en dicho material se críen hongos e insectos que pueden atentar contra la salud de las personas.

El revoque, o pañete de los muros, se hace con tierra o cemento, de acuerdo con el literal $c$ de la figura 5; no obstante, previo a la instalación se debe construir un sistema de anclaje, para que el material que se vaya a utilizar se adhiera correctamente. Esto, por su parte, consiste en incrustar tapas metálicas de botella en el centro de cada uno de los adobes, como se da a entender en el literal $b$ de la figura 5 .

\section{Discusión}

El conocimiento autóctono y ancestral de las técnicas constructivas del adobe se ha difundido de generación en generación, lo que se evidencia en viviendas, muros y construcciones realizadas con mampostería en bloques de adobe que aún no han culminado su vida útil. Teniendo en cuenta que estas piezas fueron elaboradas desde un acervo de conocimientos no codificados, surgen inquietudes: ¿cómo se han adaptado estas técnicas al lugar? ¿Cómo actúan en el contexto de los municipios de Nunchía y de Pore los distintos factores que han estimulado la desaparición de estas técnicas?

El estudio promueve el interés en esta técnica constructiva a raíz de la facilidad, la disponibilidad de los materiales y las propiedades que permiten conseguir edificaciones ambientalmente responsables, lo que atiende al Ilamado del cumplimiento de los objetivos de 
desarrollo sostenible (ODS) (ONU, 2015), a fin de disminuir los efectos del cambio climático, lo que, en la práctica, se evidencia con los datos de Aranda-Jiménez y Suárez-Domínguez (2019), quienes sustentan que se deben tener en cuenta el contexto regional y la biodiversidad en el trabajo con adobe, lo cual permite una sinergia social y un mejoramiento ambiental, teniendo como referencia el bloque de tierra comprimida (BTC), que, comparado con el ladrillo cocido, logra reducir las emisiones de dióxido de carbono $\left(\mathrm{CO}_{2}\right)$ de una tercera hasta una octava parte, dependiendo de los agregados.

La presente investigación evalúa los enfoques tanto cuantitativo - ensayos de laboratorio- como cualitativo - documentación de la observación directa- del adobe como unidad de mampostería, inherentes a la zona de afluencia geográfica de los municipios de Nunchía y de Pore, en Casanare. El primero de los enfoques se acerca a este saber desde una mirada holística que busca identificar la valoración numérica de las diferentes propiedades de los especímenes. El enfoque cualitativo, u observación directa, reconoce la perspectiva de los portadores del saber relacionados con la historia, el estilo de vida, los conocimientos empíricos y la postura frente a la pérdida gradual de esta práctica tradicional, dada la importancia de mantener vivos los saberes ancestrales, tal y como se ha trabajado con los cantos de trabajo de llano (Rivera-Salcedo y Chaparro-Barrera, 2019).

La inmersión con los pobladores arrojó precisiones de diagnóstico sobre las causas atribuibles al desvanecimiento de la riqueza intangible; principalmente, el deterioro arquitectónico-estructural y el fuerte asedio de los materiales industriales, coligado a los procesos de la modernidad, al promover el desuso del adobe como material de construcción, y obstruir así su proceso evolutivo, tal como referencia Rozo-García (2020, p. 179), inherente ello a las tecnologías disruptivas de la industria 4.0.

Se deduce que no solo el saber ancestral se disipa por motivos de los cambios en las prácticas culturales, sino por la apatía de los entes públicos gubernamentales (nacional, departamental y municipal) frente al valor de los hechos históricos, lo que se traduce en la falta de acciones de prevención y protección de estas edificaciones. Según Rivera, "no se puede olvidar que poco más del $80 \%$ del territorio colombiano se encuentra edificado sobre zonas de amenaza sísmica alta e intermedia (ahí se encuentran nuestros monumentos), donde la seguridad estructural de las edificaciones construidas en tierra es inaplazable" (2012, p.179-180).

Paralelo a esto, el Reglamento Colombiano de Construcción Sismo Resistente (NSR 10) no contempla la tierra cruda como material de construcción; por ende, tal detalle se convierte en una barrera para el uso del adobe en nuevos proyectos habitacionales, además de omitir la intervención técnica de las edificaciones elaboradas a partir del adobe y que se mantienen en pie, y argumentarse la reiterada discriminación de las construcciones en tierra cruda frente a la falta de información de las propiedades mecánicas de los materiales y sus proporciones, los métodos y las técnicas constructivas, que cobran relevancia en la etapa de evaluación de la resistencia de los elementos constructivos (Cuitiño-Rosales et al., 2020).

Por lo anterior, se requiere abordar las tecnologías convergentes de la industria 4.0 en el ámbito de lo físico, que se desarrolla desde la infraestructura y la generación de nuevos materiales, y que en términos de Schwab (2016), "son más ligeros, sólidos, reciclables, y adaptables", con las propiedades de "mitigar los riesgos globales", por lo que se advierte la modificación del saber ancestral —objeto disonante del presente estudio-, pero igualmente viable y funcional para otras disertaciones.

Es relevante la revisión de las condiciones geomorfológicas no homogéneas entre los municipios objeto del estudio, que para el caso del municipio de Nunchía se ubica en el piedemonte llanero, y cuyo paisaje posee colinas denudadas y depósitos aterrazados, cubiertos parcialmente por suelos residuales y coluviales, lo que hace frecuente la erosión en pendientes transversales pronunciadas o afectadas por procesos tectónicos (Alcaldía Municipal de Nunchía, 2017). Por otra parte, al municipio de Pore se lo considera un área cálida semihúmeda, con características menos pronunciadas de piedemonte, pero con biodiversidad de altillanura compuesta de sabanas, morichales y esteros (Alcaldía Municipal de Pore, 2017).

En relación con la sismicidad, la NSR-10 asigna el nivel intermedio para ambos municipios, que, pese a la ausencia de movimientos telúricos de alto riesgo hasta la fecha, no es motivo de omisión. Ahora bien, Colombia puede reglamentar, con base en la aplicación de las tecnologías convergentes la construcción en adobe - tal como se ha venido desarrollando en Perú ${ }^{1}$ y en otros países-, que demanda la urgente conservación de este conocimiento, mediante la adopción de intereses turísticos y monumentos históricos y culturales, además del uso habitacional, en concordancia con las experiencias de formalización de licencias constructivas en Barichara, Santander, Colombia, sugerido por Rivero-Bolaños (2007).

La valoración realizada establece como factible seguir con el desarrollo de proyectos constructivos a base de adobe, no sin antes ahondar

1 Norma E.080 "Diseño y construcción con tierra reforzada" emitida por el Ministerio de Vivienda, Construcción y Saneamiento del Perú; se orienta al diseño, la construcción, la reparación y el reforzamiento de edificaciones de tierra. 
en la manera de optimizar o mejorar su capacidad de resistencia ante posibles eventualidades de orden climatológico y sísmico, buscando así que la normatividad nacional lo valide como conocimiento formal y revalorice la tierra cruda como material apto para la edificación de viviendas urbanas y rurales.

Se busca promover la conservación de los saberes ancestrales como legado inmaterial en dos municipios de la región de la Orinoquía y exaltar las condiciones óptimas de calidad de vida que ofrecen dichas construcciones en tierra cruda. Este es un llamado a incorporar los resultados obtenidos en las agendas institucionales del país, tal como lo expresan Rivera y Chaparro: "faltan alternativas e institucionalidad que se ocupen de trabajar por el reconocimiento de la memoria colectiva, el fomento y divulgación de las costumbres y tradiciones de la cultura llanera en las agendas familiares, culturales, políticas y sociales" (2019, p. 149). Se hace necesario seguir avanzando en un marco legal que, además de avalar este tipo de edificaciones, dé las bases técnicas para su construcción y su rehabilitación.

\section{Conclusiones}

Actualmente la arquitectura vernácula de los municipios de Nunchía y Pore se ha descontextualizado en cuanto a la cultura, su entorno físico, su tipología y su técnica constructiva; todo ello se hace evidente en la observación directa realizada. Los vestigios del saber ancestral de las técnicas constructivas en adobe que se encontraron de los últimos 20 años muestran la oportunidad para su conservación por medio de sus sabedores y de la evidencia física. Lo anterior guarda coherencia con lo estipulado en el Decreto 2113 (2019) para la protección del patrimonio de interés cultural declarado. Se rescata y se reconoce el valor del adobe como material constructivo, y cuyas pautas de elaboración y uso permitieron esquematizar guías que detallan la pieza de mampostería, descritas a través de un arquetipo de vivienda autóctona.

Las propiedades estructurales básicas a muestras de adobe obtenidas en los municipios de Pore y Nunchía fueron determinadas a través de la caracterización física, mecánica y química, lo que permitió identificar las propiedades de resistencia a la compresión, teniendo en cuenta aspectos como: tipo y cualidades del suelo, aditivos naturales, composición porcentual de arenas, limos y arcillas, y humedad óptima.

Como una referencia a la reivindicación de la construcción en tierra, se puede observar la obra y el manifiesto del arquitecto colombiano Herberth Baresh, quien rompió con el paradigma de los "materiales nobles" y estudió el uso del adobe aplicado de manera exitosa a viviendas de estratos altos, lo que dio valor al material en sus diseños y relacionó el proyecto con la cultura y el entorno. Para poder avanzar hacia la transformación sostenible, se propone: reorganizar la construcción como flujo de aprendizajes colectivos; reconocer a los sabedores; analizar y estudiar los recursos disponibles en función del mejoramiento del hábitat, y pensar la arquitectura de manera eficiente desde lo local, y concertada con los usuarios, quienes deben conocer las técnicas y estar capacitados para el mantenimiento de las casas, a la vez que, promover el trabajo colaborativo y estimular las redes comunitarias (JaramiIlo-Benavides et al., 2019).

Ante la pérdida del saber ancestral, las casas en adobe de los municipios de Pore y Nunchía han ido quedando abandonadas, por las bondades y los beneficios asociados a materiales industriales respecto a los cuales, según los resultados, el principal indicador (57\%), se refiere a "Valores como, la higiene, la 'firmeza' y durabilidad" (Barada, 2014). La segunda causa (37\%) es el desconocimiento de los procesos de mantenimiento y reparación de casas en adobe, de lo cual se deduce que, culturalmente, el uso de "nuevos materiales" se relaciona con el "progreso", lo cual, a su vez, propone la búsqueda de estrategias de sensibilización frente a la percepción de la técnica constructiva, como primer paso para analizar las tecnologías aplicadas a la vivienda rural, que permita reiniciar y reorientar la arquitectura del lugar hacia una correcta transformación de las técnicas constructivas ancestrales a partir del entorno y la cultura.

Es necesario aprender de la arquitectura vernácula de la región aquello que le es propio, como las lógicas que expresa el lugar con su entorno y su paisaje, las enseñanzas manifiestas en su técnica y los aspectos sociales y culturales que lo rodean, a fin de superar los prejuicios frente a la construcción en tierra, y de esta manera retomar y mejorar las prácticas ancestrales.

\section{Contribuciones}

Los autores del presente escrito estamos afiliados institucionalmente, y hemos realizado el estudio de manera interdisciplinaria desde los programas de Arquitectura e Ingeniería Civil y el Departamento de Humanidades, y compartido en su totalidad las temáticas tratadas en el documento; a saber: introducción, análisis de resultados, discusión y conclusiones. En relación con el análisis de los datos, dos autores desarrollaron dicho ítem. Para la organización, la referenciación y la redacción del documento, dos autores se encargaron de las respectivas versiones y de los ajustes a ellas. En la elaboración y la edición de las tablas y las figuras, estas fueron realizadas por tres autores. 


\section{Referencias}

Alcaldía Municipal de Nunchía. (2012). Decreto No. DA0100.02.01.022. Por medio del cual se adopta el Plan de Desarrollo del Municipio de Nunchía "Marcando la Diferencia" para el periodo 2012-2015

http://www.nunchia-casanare.gov.co/ Transparencia/Normatividad/Decreto $\% 20$ N\%C2\%B0\%20022\%20de\%202012.pdf

Alcaldía Municipal de Nunchía. (2017). Información del Municipio.

http://www.nunchiacasanare.gov.co/ MiMunicipio/Paginas/Informacion-delMunicipio.aspx

Alcaldía Municipal de Pore. (20 de octubre de 2017). Nuestro municipio.

http://www.pore-casanare.gov.co/municipio/ nuestro-municipio

Aranda-Jiménez, Y. y Suárez-Domínguez, E. (2019). La huella de carbono en elementos de arquitectura con tierra. Seminario Iberoamericano de Arquitectura y Construcción con Tierra, 19. Memorias digitales de los SIACOT. San Salvador, El Salvador, FUNDASAL/ PROTERRA. p. 119-126.

Barada, J. (2014). Transformaciones vernáculas: Cambios y continuidades en las arquitecturas locales de la Puna Argentina. Arquitecturas del Sur, 32(46), 6-17.

http://revistas.ubiobio.cl/index.php/AS/ article/view/738/699

Barada, J. (2016). La construcción de una casa de pueblo. Formas de producción, técnicas y espacios a partir de un estudio de caso en la Puna argentina (Coranzulí, Jujuy). Estudios Sociales del NOA, (18), 31-60. http://revistascientificas.filo.uba.ar/index.php/esnoa/ article/view/4218/3754

Castiblanco-Roldán, A. F. (2009). Ciudad y memoria: los monumentos y la cultura popular de la Bogotá de fines de siglo XIX y principios del XX. Revista Colombiana de Educación (57), 46-76.

https://revistas.pedagogica.edu.co/index. php/RCE/article/view/7589/6104

Congreso de la República de Colombia. (12 de julio de 2018). Ley 1916 de 2018. http:// svrpubindc.imprenta.gov.co/diario/index. xhtml; jsessionid $=99967 f 249 b d 23683 \mathrm{c}$ 6497dccf3c7

Cuitiño-Rosales M. G., Rotondaro R., y Esteves A. (2020). Análisis comparativo de aspectos térmicos y resistencias mecánicas de los materiales y los elementos de la construcción con tierra. Revista de Arquitectura (Bogotá), 22(1). https://doi.org/10.14718/RevArq.2020.2348

Departamento Administrativo Nacional de Estadística (15 de septiembre de 2015). Censo acional Agropecuario 2014, [Tercera entrega]. https://www.dane.gov.co/files/ CensoAgropecuario/entrega-definitiva/ Boletin-3-Viviendas-hogares-y-personas/3 Presentacion.pdf

Duarte, C.G., Alcindor, M., y Correia, M. (2018). Arquitectura tradicional de tierra en Europa: un patrimonio de entramado y encestado, adobe, tapia y pared de mano. Anales del Instituto de Arte Americano e Investigaciones Estéticas. Mario J. Buschiazzo, 48(2), 239-256. http://www.scielo.org.ar/scielo.php?script=sci arttext\&pid=S2362-20242018000200009 $\& \operatorname{lng}=\mathrm{es} \& \operatorname{lng}=\mathrm{es}$.
Jaramillo-Benavides, A. S., Patricio-Karnopp, Z. M. y Ilha-Librelotto, L. (2019). Durabilidad de los materiales naturales de construcción: percepciones de proyectistas constructores y usuarios en Florianópolis Brasil. Revista de Arquitectura (Bogotá), 21(2), 89-100. https://doi.org/10.14718/RevArq.2019.21.2.1825

Martínez-Soto, J. (2019). La ciudad: una visión desde la psicología ambiental. Quivera Revista de Estudios Territoriales, 21(1), 43-57. https://doi.org/10.36677/qret.v21i1.11490

Ministerio de cultura de Colombia. (12 de diciembre de 2014). Resolución 3914 de 2014. http://svrpubindc.imprenta.gov.co/diario/ view/diarioficial/consultarDiarios.xhtml

Ministerio de vivienda, ciudad y terriotorio. (25 de noviembre de 2019). Decreto 2113 de 2019.

http://svrpubindc.imprenta.gov.co/diario/ view/diarioficial/consultarDiarios.xhtml

Ministerio de Vivienda, Construcción y Saneamiento. (5 de abril de 2017). Norma E.080 Diseño y construcción con tierra reforzada. Anexo. Resolución Ministerial No 121-2017-Vivienda.

https://www.sencico.gob.pe/descargar. php?idFile $=3478$

Morales-Galaviz, G. (2017). Caracterización del comportamiento térmico de un sistema constructivo de tierra cruda aplicado en prototipos: caso de estudio, localidad, Aquixtla, Puebla. [Tesis de maestría, Universidad Autónoma Metropolitana Azcapotzalco]. Repositorio Institucional Zaloamatí. h t t p ://zaloamati.azc.uam.mx/ bitstream/handle/11191/6003/ Caracterizacion_del_comportamiento_ termico Morales Galaviz G 2016. pdf? sequence $=1 \&$ isAllowed $=y$

Morales-Morales, R., Torres-Cabrejos, R., Rengifo, L., y Irala-Candiotti, C. (1993, marzo). Manual para la construcción de viviendas en adobe. Universidad Nacional de Ingeniería (UNI).

https://209b95ce-a-62cb3a1a-s-sites.googlegroups.com/site/elmundodelasobrasciviles 5/Home/tecnologias/MANUALDECONSTRUCCIONENADOBE. pdf?attachauth $=$ ANoY7cr $7 \mathrm{LByJ} 7 \mathrm{fKL} 78 \mathrm{~m}$ jHDJiXsvAncl3xbSN89CYūWVysAQWayhiJqlckCXW3QENd7yRL5brEFzKMy_uneMQe4GUjyYSvuPOmp2I8FWtEs1wA8MVF3umRa7cAL_yRu7BltfL3GRYT5_x26QKwJHc5sB7yQLv L5hW7fZId3y1 S Scxhw8OFYc4JAKILp5Hq-Cx6HF3Rohzkxkz4090sdpaysXjzY3iGWqyysMa1Ed36yHZNyWu7qF VJEjOX2WCcry2j44JL7TLO835SCvV50JU4O8zE0Q1xg\%3D\%3D\&attredirects $=0$

Organización de las Naciones Unidas (2015). Objetivos de desarrollo sostenible. https://www.undp.org/content/undp/es/ home/sustainable-development-goals.html

Rivera-Salcedo, H., y Chaparro-Barrera, A (2019). Sobre los procesos de enseñanza-aprendizaje en el legado de los Cantos de Trabajo de llano, patrimonio cultural inmaterial de la Orinoquia. Cultura, Lenguaje y Representación, (21)139-140.

http://www.e-revistes.uji.es/index.php/clr/ article/view/3797/3139
Rivera, H., Daza, A., y Plazas, G. (2018). Caracterización del saber ancestral del uso del adobe en construcciones autóctonas en los municipios de Nunchia y Pore del departamento de Casanare [manuscrito no publicado]. Grupo de investigación Biohábitat, Fundación Universitaria Internacional del Trópico Americano.

Rivera-Torres, J. (2012). El adobe y otros materiales de sistemas constructivos en tierra cru da: caracterización con fines estructurales. Apuntes: Revista de Estudios sobre Patrimonio Cultural - Journal of Cultural Heritage Studies, 25(2), 164-181.

http://www.scielo.org.co/scielo.php?pid=S1657 $97632012000200002 \& \mathrm{script}=\mathrm{sci}$ arttext\&tlng $=$ pt

Rivero-Bolaños, S. (2007). El uso masivo de la tierra como material de construcción en Colombia. Apuntes. Revista de Estudios sobre Patrimonio Cultural, 20(2), 354-356. https://revistas.javeriana.edu.co/index.php/ revApuntesArq/article/view/8990

Rozo-García, F. (2020). Revisión de las tecnologías presentes en la industria 4.0. Revista UIS Ingenierías, 19(2), 177-192.

https://doi.org/10.18273/revuin.v19n2 2020019

Saroza, B., Rodríguez, M. A., Menéndez, J. M., y Barroso, I. J. (2008). Estudio de la resistencia a compresión simple del adobe elaborado con suelos procedentes de Crescencio Valdés, Villa Clara, Cuba. Informes de la Construcción, 60(511), 41-47. https://doi.org/10.3989/ic.2008.v60 i511.745

Schwab, K. (2016), La cuarta revolución industrial. Editorial Debate.

http://40.70.207.114/documentosV2/ La\%20cuarta\%20revolucion\%20industrialKlaus\%20Schwab\%20(1).pdf

Torres-Peceros, H. E. (2018). Reflexiones acerca de la Arquitectura Precolombina en el Perú. Anales del Instituto de Arte Americano e Investigaciones Estéticas. Mario J. Buschiazzo, 48(2), 157-170.

http://www.scielo.org.ar/scielo. php?script $=$ sci arttext \&pid $=$ S 2362 20242018000200004\&lng=es\&tlng=es

Varela, P. (2014, 13 de julio). Cortar madera en luna menguante. El País.

https://elpais.com/diario/2004/07/13/ madrid/1089717874 850215.htm

Villacampa-Crespo, L., García-Soriano, L., Vegas López-Manzanares, F., y Mileto, C. (2018). Constructive techniques of the past for a susConstructive future. The case of traditional earthen architecture in Aragon (Spain). International Journal of Latest Trends in Engineering and Technology (Online), 11(3), 30-36. https://www.ijltet.org/journal/153848668505.\%20 2676.pdf 
A Portada: Catedral de Notre Dame de Paris durante los trabajos de reparación en octubre de 2020 Fotografía: Arquitecto Andrés Avila Gómez (octubre, 2020)
(A) Orientación editorial

\section{Enfoque y alcance}

La Revista de Arquitectura (Bogotá) ( (ISSN 1657-0308 Impresa y E-ISSN 2357-626X en línea) es una publicación científica seriada de acceso abierto, arbitrada mediante revisión por pares (doble ciego) e indexada, en donde se publican resultados de investigación originales e inéditos.

Está dirigida a la comunidad académica y profesional de las áreas afines a la disciplina. Es editada por la Facultad de Diseño y el Centro de Investigaciones (CIFAR) de la Universidad Católica de Colombia en Bogotá (Colombia).

La principal área científica a la que se adscribe la Revista de Arquitectura (Bogotá) según la OCDE es:

Gran área: 6. Humanidades

Área: 6.D. Arte

Disciplina: 6D07. Arquitectura y Urbanismo

También se publican artículos de las disciplinas como 2A02, Ingeniería arquitectónica; 5G03, Estudios urbanos (planificación y desarrollo); 6D07, Diseño.

Los objetivos de la Revista de Arquitectura (Bogotá) son:

- Promover la divulgación y difusión del conocimiento generado a nivel local, nacional e internacional

- Conformar un espacio para la construcción de comunidades académicas y la discusión en torno a las secciones definidas.

- Fomentar la diversidad institucional y geográfica de los autores que participan en la publicación.

- Potenciar la discusión de experiencias e intercambios científicos entre investigadores y profesionales.

- Contribuir a la visión integral de la arquitectura, por medio de la concurrencia y articulación de las secciones mediante la publicación de artículos de calidad.

- Publicar artículos originales e inéditos que han pasado por revisión de pares, para asegurar que se cumplen las normas éticas, de calidad, validez científica, editorial e investigativa.

- Fomentar la divulgación de las investigaciones y actividades desarrolladas en la Universidad Católica de Colombia.
Palabras clave de la Revista de Arquitectura (Bogotá): arquitectura, diseño, educación arquitectónica, proyecto y construcción, urbanismo.

Idiomas de publicación: español, inglés, portugués y francés.

Título abreviado: Rev. Arquit.

Titulo corto: RevArq

\section{Políticas de sección}

La revista se estructura en tres secciones correspondientes a las líneas de investigación activas y aprobadas por la institución, y dos complementarias, que presentan dinámicas propias de la Facultad de Diseño y las publicaciones relacionadas con la disciplina.

Cultura y espacio urbano. En esta sección se publican los artículos que se refieren a fenómenos sociales en relación con el espacio urbano, atendiendo aspectos de la historia, el patrimonio cultural y físico, y la estructura formal de las ciudades y el territorio.

Proyecto arquitectónico y urbano. En esta sección se presentan artículos sobre el concepto de proyecto entendido como elemento que define y orienta las condiciones proyectuales que devienen en los hechos arquitectónicos o urbanos, y la forma como estos se convierten en un proceso de investigación y nuevo de conocimiento. También se presentan proyectos que sean resultados de investigación, los cuales se validan por medio de la ejecución y transformación en obra construida del proceso investigativo. También se contempla la publicación de investigaciones relacionadas con la pedagogía y didáctica de la arquitectura, el urbanismo y el diseño.

Tecnología, medioambiente y sostenibilidad. En esta sección se presentan artículos acerca de sistemas estructurales, materiales y procesos constructivos, medioambiente y gestión, relacionados con los entornos social-cultural, ecológico y económico.

Desde la Facultad. En esta sección se publican artículos generados en la Facultad de Diseño, relacionados con las actividades de docencia, extensión, formación en investigación o internacionalización, las cuales son reflejo de la dinámica y de las actividades realizadas por docentes, estudiantes y egresados; esta sección no puede superar el $20 \%$ del contenido.

Textos. En esta sección se publican reseñas, traducciones y memorias de eventos relacionados con las publicaciones en Arquitectura y Urbanismo.
A Frecuencia de publicación

Desde 1999 y hasta el 2015, la Revista de Arquitectura (Bogotá) publicó un volumen al año, a partir del 2016 se publicarán dos números por año en periodo anticipado, enero-junio y julio-diciembre, pero también maneja la publicación anticipada en línea de los artículos aceptados (versión Post-print del autor).

La Revista de Arquitectura (Bogotá) se divulga mediante versiones digitales (PDF, HTML, EPUB, XML) e impresascon un tiraje de 700 ejemplares, los tiempos de producción de estas versiones dependerán de los cronogramas establecidos por la editorial.

Los tiempos de recepción-revisión-aceptación pueden tardar entre seis y doce meses dependiendo del flujo editorial de cada sección y del proceso de revisión y edición adelantado.

Con el usuario y contraseña asignados, los autores pueden ingresar a la plataforma de gestión editorial y verificar el estado de revisión, edición o publicación del artículo.
(A) Canje

La Revista de Arquitectura (Bogotá) está interesada en establecer canje con publicaciones académicas, profesionales o científicas del área de Arquitectura y Urbanismo, como medio de reconocimiento y discusión de la producción científica en el campo de acción de la publicación.

Mecanismo

Para establecer canje por favor descargar, diligenciar y enviar el formato: RevArq FP20 Canjes

Universidad Católica de Colombia
(202I, enero-junio). Revista de
Arquitectura (Bogotá), 23(I),
I-I24. Doi: 10.14718

ISSN: I657-0308
E-ISSN: 2357-626X
Especificaciones:
Formato: $34 \times 24 \mathrm{~cm}$
Papel: Mate II5 g
Tintas: Negro y policromía

Contacto

Dirección postal:

Avenida Caracas No. 46-72

Universidad Católica de Colombia

Bogotá D. C., Colombia

Código postal: 111311

Facultad de Diseño

Centro de Investigaciones (CIFAR)

Sede El Claustro. Bloque "L", 4 piso

Diag. 46A No. 15b-10

Editor, Arq. César Eligio-Triana

Teléfonos:

+57 (1) $3277300-3277333$

Ext. 3109; 3112 o 5146

Fax: +57 (1) 2858895
Correo electrónico:

revistadearquitectura@ucatolica.edu.co cifar@ucatolica.edu.co

Página WEB:

www.ucatolica.edu.co

Vínculo Revistas científicas

http://publicaciones.ucatolica.edu.co revistas-cientificas

https://revistadearquitectura.ucatolica.edu.co/ 
Reflexiones en torno a la enseñanza de la arquitectura y el urbanismo en Colombia. Conversaciones con Juan Carlos

m. Pérgolis Valsecchi, René Carrasco Rey y Juan Carlos del

¿ Castillo

Reflections on the teaching of architecture and urban planning in Colombia. Conversations with Juan Carlos Pérgolis Valsecchi, René Carrasco Rey y Juan Carlos del Castillo

웅

La experiencia de caminar en ciudades latinoamericanas

The experience of walking in Latin American cities

Movilidad urbana de la población en la ciudad de Encarnación * Paraguay. Desarrollo urbano y gestión ambiental

$m$ Urban mobility of the population in the city of Encarnación, Paraguay.

这

ษั

La vivienda adecuada financiada según el ingreso.

El discurso de las Naciones Unidas

பं

La arquitectura frente a las innovaciones pedagógicas.

Pervivencia y resignificación de la Escuela Nueva en el Cono Sur Architecture facing the pedagogical innovations. Survival and resignification of the New School in the Southern Cone

Aporte de las competencias investigativas a la integración de saberes curriculares.

Una visión en el escenario de aprendizaje del diseño

arquitectónico

Contribution of research competencies to the integration of curricula knowledge. A vision in the architectural design learning scenario

Adobe como saber ancestral usado en construcciones

N autóctonas de Pore y Nunchía, Casanare (Colombia)

j. Adobe as an ancestral knowledge used in autochthonous constructions $\stackrel{4}{\longleftarrow}$

Paisaje construido y sustentabilidad urbana: huellas

$œ$

El Plan de Transformación de Osorno

Built landscape and urban sustainability: Identity prints of the modern landscape. The Osorno Transformation Plan

Indicadores de sostenibilidad social y su relación con el

$\hat{a}$

ن்

노 caso de estudio en Cuenca (Ecuador)

ن

Confort térmico en vivienda social multifamiliar de clima cálido en Colombia

느 Thermal comfort in multi-family social housing in a warm climate in ن் Colombia
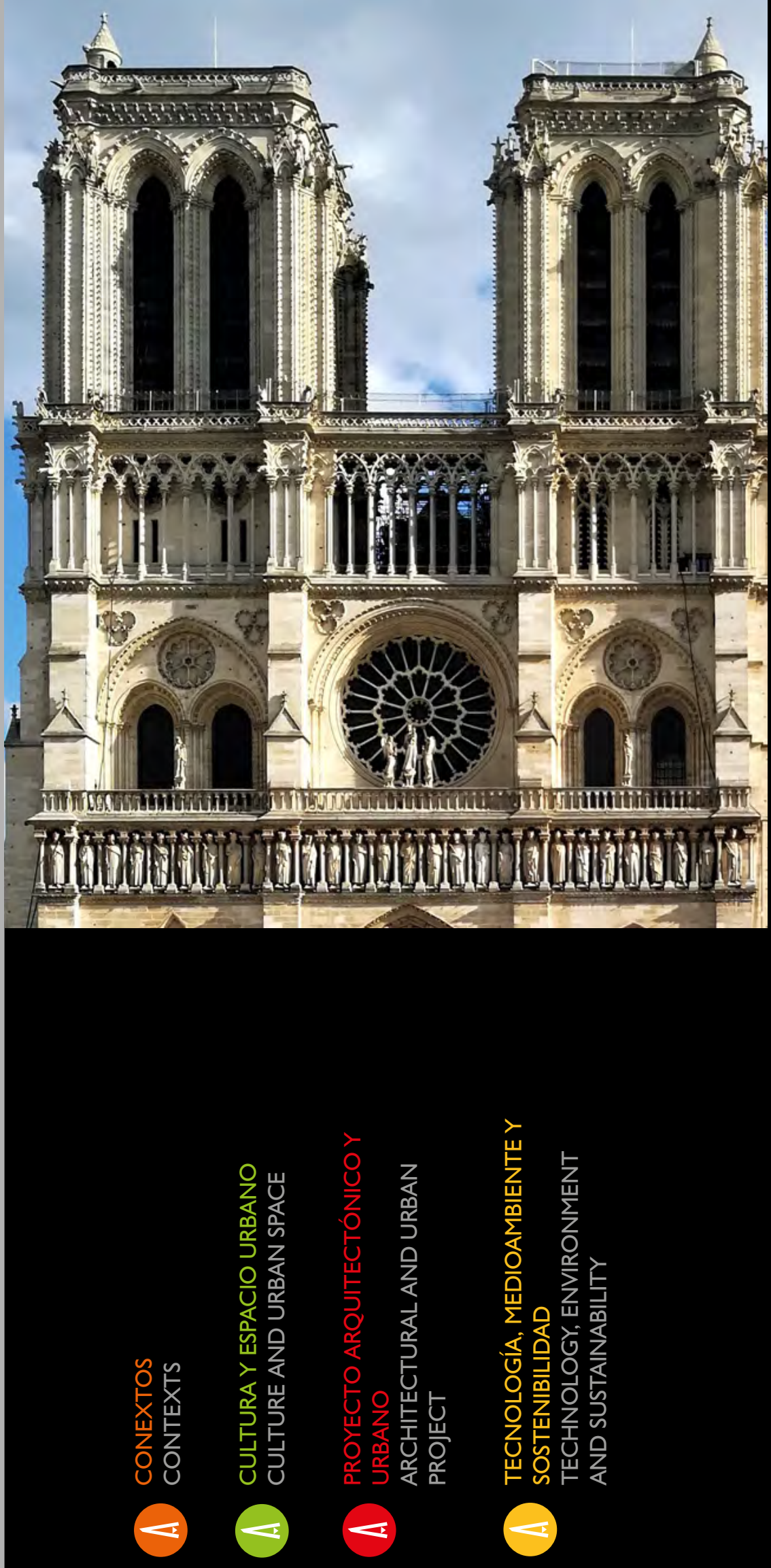

La Revista de Arquitectura es de acceso abierto, arbitrada e indexada y está presente en:
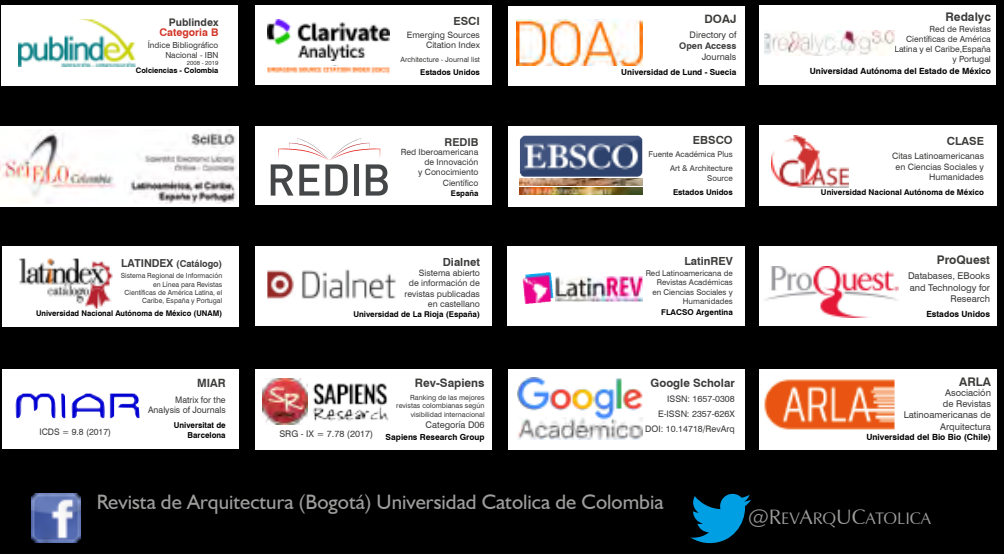

8
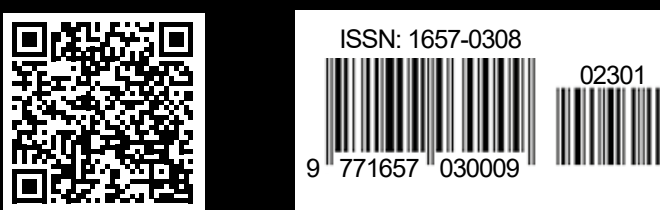